\title{
Research on Enterprise Brand Innovation based on Strategic Marketing
}

\author{
Yi Yang, Long Cheng, Rui Zhang \\ Xi'an University of Technology, Xi'an, Shaanxi, 710054
}

\begin{abstract}
Brand strategic marketing, as the name suggests, is the enterprise to create, use and maintenance of the brand as the core, in the analysis of their own conditions and the external environment on the basis of the designated enterprise overall action plan. The success of the brand depends on the organic integration of the diversified business elements of the enterprise. From the strategic point of view, this system integration includes four aspects: the product and the market level of the battalion (Capital) level, business system and cultural level of the camps of integration and the organic integration between the above three levels. New 21 century, the new marketing environment, Chinese enterprises should be when its brand Multi-faceted strategic adjustment.
\end{abstract}

Keywords: Strategic marketing, Brand Innovation, Enterprise Finance

\section{Introduction}

The so-called brand marketing refers to the creation of the brand, the brand into a brand name, to consolidate and enhance the competitiveness and value of the brand as the core content of the marketing activities and processes. In appearance, a brand is a name, a term, a symbol, a symbol, or a design, or a combination thereof, that identifies the goods or services of a seller (or a group). But in essence, the brand is a system, is a comprehensive reflection of the market competitiveness of enterprises. Brand as a system, mainly by the following three subsystems: 1. Products and services and functions (use, quality, price, packaging. 2. Enterprise and product image (internal image, logo, music, advertising, color ...); .i Shaw psychology (cognition, attitude, emotion, experience ...). Brand 
reflects the strength of the enterprise market competition, including: the ability to observe and judge the market for business investment planning and decisionmaking capabilities, (Communication), marketing service ability, marketing channel expansion and control ability, etc. Therefore, from the system point of view, brand marketing is such a marketing activities and processes: in the dynamic (marketing), marketing, To understand the marketing environment on the basis of a specific product and service functions, specific corporate and product image, impact and develop a specific consumer psychology, resulting in enterprises with independent intellectual property rights, the obvious market attractiveness and competitive advantage Brand in this sense, brand marketing is a kind of cultivation and management of the brand as the core systems engineering.

\section{Strategic marketing management theory logical system framework}

The objective socio-economic factors influencing the development and evolution of marketing management theories are manifold and vary with the times. However, the common and most important characteristics of consumer demand, which are determined by the relationship between supply and demand, The changing trend of human living environment and its changing trend, the role of enterprises and their changing trends. These factors in the contemporary society were showing some new features, they put forward new requirements for marketing management theory, thus promoting the traditional marketing management theory to strategic marketing management theory leap. First of all, the relationship between supply and demand of consumer demand characteristics and trends determined to play a decisive role. Although there are many people hungry, but because of the development of science and technology to promote the development of productive forces, on the whole, the world's advanced productive forces on behalf of the developed countries market oversupply situation has become an irreversible phenomenon and trend of consumer consumption level Improve the consumer demand alienation phenomenon, the consumer business and society put forward higher requirements, that is, through the daily consumption of basic material needs to meet at the same time, but also to meet the spiritual needs. In other words, consumers are no longer simply based on the order from the material to the spirit to meet the needs, but to meet the basic material and spiritual needs of both the transition phase, and some developed countries have completed this transition.

Second, the human living environment and the changing trend of the formation of external pressure. With the acceleration of science and technology to mankind bring such and such benefits, along with human conquest and transformation of natural ability, coupled with human activities on their own natural society may not bring harm awareness along with this conquest ability together Improve, resulting in the deterioration of human living environment, so 
that mankind is facing unprecedented challenges, and there have been many technological progress alone can not solve the problem. In particular, the rapid expansion of population and the increasing pressure on the environment and the supply of resources, as a result of population growth, people to meet their own unlimited desire for material needs, continue to consume the Earth's limited resources, While the environment to the discharge of various waste, mainly waste gas, waste water, waste residue, the human living environment deteriorating environmental pollution is becoming increasingly serious; forest resources plummeted, serious degradation of land resources, forest once covered more than $40 \%$ of the earth Land, and now its area has been reduced by one third; global warming trend is obvious, and so on. Finally, the role of business changes, that is, from the original "economic man" role into the modern society required "social man" (economic society, the following) role. The change of enterprise role from "economic person" to "social person" is due to the change of the enterprise itself in the system, scope of activities and the objective social and economic environment changes that it relies on for survival and development. First, the enterprise of natural, human, social influence with the progress of science and technology gradually increased, has now reached an unprecedented level. Second, enterprises need to face the business needs of the public more and more interdependence between them more and more close, they vary to varying degrees, directly or indirectly affect the business situation, and even the survival of enterprises And development. Third, the long-term survival and development of enterprises on the natural environment and social environment has undergone profound changes, the former as we described in the previous one hundred years of human behavior has increased the infinite human needs and natural resources supply Such as "human consumption" and "green consumption" to meet the requirements of the modern objective social and economic environment, such as the new concept of consumption, and so on, such as the human consciousness, the consumer matures.

\section{The Formation of Enterprise's Brand Strategic marketing}

As the strategic marketing concept of corporate marketing activities, the object is the overall image of the enterprise, corporate image is the overall business information on the organic combination of various reflections in people's minds, is a phenomenon of consciousness, so there must be a tangible and can Including the corporate image of the various content of the material carrier to express and intuitively test the strategic marketing concept of its overall image of the "design, dissemination, maintenance and improvement" effect, this material carrier is a corporate brand. Brand as a symbol, it can pass six aspects of information (Philip Kotler, 1997, Mei Ru and other translation): attributes, interests, values, culture, personality, users. In short, the brand is the organic combination of enterprise information. These attributes of the brand determines that it can become the material carrier of corporate image under the concept of strategic marketing. The brand-name corporate strategy is the corporate brand as a corporate image of the 
material carrier to take a variety of marketing activities in the process. Brand strategy is the core of brand strategy, brand life cycle theory, as well as the law of life cycle according to the brand of information dissemination strategy and strategy issues.

After the second half of the twentieth century, the birth of the knowledge economy as a new economic form has begun to show vitality, knowledge of the 21 st century is undoubtedly the knowledge economy, knowledge and information production, storage, use and consumption will be The basis and the mainstream of social development in the new century. The advent of knowledge economy is leading to a revolution in enterprise marketing - knowledge marketing is a brandnew marketing idea of creating, using, storing, upgrading and transforming knowledge and intelligence, Which integrates information technology, market forecasting, R \& D, marketing decision and so on to reflect the quality of people and the main link of intellectual resources.In order to meet the challenges of knowledge economy, Chinese enterprises should be integrated into the brand marketing knowledge marketing concepts and strategies: .2 focus on brand and product to meet the customer's knowledge needs; 2. Increase the brand and product knowledge content, brand and product innovation with knowledge and constantly improve the differentiation and other competitive advantages, and to increase consumer value; 3 . Excavate brand and product of cultural connotation, resulting in the concept and value orientation caused strong resonance of consumers; 4. Cultivate and foster knowledge-based marketing team, the brand marketing process more suitable for high-tech products, intelligent and demand Personalized requirements.

Quality service. First, high-quality services can promote product sales, thereby expanding the visibility of enterprises and their brands; Secondly, improve the quality of services to customers to reduce the purchase of the wrong, improper use, timely treatment and solve customer problems on the product, which can Reduce customer risk and loss, with the maintenance of corporate and brand reputation of the role; Third, improve the quality of services can increase the interests of customers, such as free shipping, maintenance, training and so on. In addition, improve the quality of service is the enterprise to express the respect of the best way to customers, access to great psychological satisfaction.

Maintenance strategy is the product brand and good reputation on the basis of the enterprise through the use of internal and external resources available to the management of the brand. Brand maintenance strategy should be to strengthen management, innovation, provide a solid foundation for the brand, and the use of legal weapons and other means to protect the brand from infringement, to ensure that their preservation and appreciation. Without a maintenance strategy, the brand will be difficult to perpetuate in the market forever.

Timely registration. Enterprises should apply for trademark registration before the product is put on the market. At the same time, in time to the product importing country registered trademarks, for the products to enter foreign markets to prepare. 
Defensive registration. To prevent the trademark of others to borrow corporate brand awareness and investment in advertising and so on, to share the brand of intangible assets, which is the enterprise must pay attention to.

Timely renewal. China $<<$ Trademark Law $>>$ stipulates that: a registered trademark is valid for 10 years, 6 months before the expiration of the application should be renewed registration, during which no application can be granted a grace period of 6 months, over the grace period did not apply Renewal of the loss of trademark rights.

\section{Some suggestions on brand strategic marketing of enterprises}

After the second half of the twentieth century, the birth of the knowledge economy as a new economic form has begun to show vitality, knowledge of the 21 st century is undoubtedly the knowledge economy, knowledge and information production, storage, use and consumption will be The basis and the mainstream of social development in the new century. The advent of knowledge economy is leading to a revolution in enterprise marketing - knowledge marketing is a brandnew marketing idea of creating, using, storing, upgrading and transforming knowledge and intelligence, Which integrates information technology, market forecasting, R \& D, marketing decision and so on to reflect the quality of people and the main link of intellectual resources. In order to meet the challenges of knowledge economy, Chinese enterprises should be integrated into the brand marketing knowledge marketing concepts and strategies: .2 focus on brand and product to meet the customer's knowledge needs; 2 . Increase the brand and product knowledge content, brand and product innovation with knowledge and constantly improve the differentiation and other competitive advantages, and to increase consumer value; 3 . Excavate brand and product of cultural connotation, resulting in the concept and value orientation caused strong resonance of consumers; 4. Cultivate and foster knowledge-based marketing team, the brand marketing process more suitable for high-tech products, intelligent and demand Personalized requirements.

Since the mid-90s of the 20th century, e-commerce and network marketing was accelerating development trend. Into the 21 st century, the Internet and other computer networks will be more extensive and more rapid penetration into the social, political, economic, cultural every corner, into people's daily lives, and bring about global production and lifestyle changes More and more enterprises have to seize the high ground of electronic commerce and network marketing, and regard network marketing as the main way to gain the competitive advantage in the future. In this paper, However, the network marketing as a brand new way of marketing, and can not change the brand to meet customer needs and corporate marketing competition in the position and role. Therefore, in the face of the coming network civilization, Chinese enterprises in brand marketing should With the advantages and characteristics of network marketing, and continue to build and strengthen their own brand, in order to compete in the network era of the market for better survival and development. For example, the domain name 
management, Web site and web management as an important content of brand management, And through the domain name, website and website, publicity corporate culture and business philosophy, showcase their products, services and style for the corporate brand to attract more "attention resources", the establishment of the brand in the online consumer high profile; Internet powerful multimedia interactive communication function, allowing consumers to participate in product design, at any time to understand and meet consumers in the selection, purchase and use of personalized needs, so as to establish the brand in the online consumer's high reputation.

\section{Conclusion}

Strategic marketing emphasizes the strategic position of the development of marketing plans to achieve sustainable development of competitive advantage, which is characterized by research enterprises how to effectively differentiate and competitors. Brand Value A measure of the intrinsic utility of a customer, which is designed to provide the company with a continuous, differentiated advantage over its competitors. The establishment of brand value is one of the keys to strategic marketing. In this paper, the brand value theory as the starting point, the brand value creation as the core of the enterprise strategic marketing implementation plan to help enterprises improve the core competitiveness.

\section{Acknowledgement}

Fund Project: Soft Science Research Program of Shaanxi Province (2016KRM135)

Fund Project: Special Program of Scientific Research Plan of Education Department of Shaanxi Province (15JK1539)

\section{References}

[1] Zhang Jianping. Air conditioning Co., Ltd. brand strategic marketing to build. China market, 23(6), pp. 10-11, 2015.

[2] Qiao Bin, Chen rush, Wang Danxu, Jin Zhenhua.Yanbian rice brand strategic marketing. Modern Business, 26(2), pp. 26-32, 2015.

[3] Zhang Biao. The corporate brand strategic marketing. Modern Business., 18(3), pp. 2-8, 2010.

[4] on the role of corporate brand strategic marketing and implementation. Paper Information, 10(6), pp. 32-36, 2010.

[5] Meng Xianzhong. Analysis of the role of enterprise brand strategic marketing and implementation China Science and Technology Wealth, 6(1), pp. 17-23, 2009. 